\title{
КОРРЕЛЯЦИЯ ИСХОДОВ ЛЕЧЕНИЯ БЕСПЛОДИЯ МЕТОДОМ ЭКСТРАКОРПОРАЛЬНОГО ОПЛОДОТВОРЕНИЯ (ЭКО) ОТ МАССЫ ТЕЛА У ЖЕНЩИН РЕПРОДУКТИВНОГО ВОЗРАСТА
}

\author{
Витязева И.И., Дружинина А.С., Красовская Р.Л. \\ ФГБУ «НМИЦ эндокринологии» Минздрава России
}

По данным ВОЗ от 2016 г., 39\% взрослого населения имели избыточный вес, около 13\% -ожирение. Избыточная масса тела (ИзбМТ) и ожирение у женщин часто являются причинами нарушения менструальной функции, вплоть до ановуляции, бесплодия, высокой частоты гиперплазии эндометрия. Частота развития ожирения у детей, рожденных от матерей с индексом массы тела (ИМТ) >30 кг/M² выше, чем у пациенток с нормальной массой тела (НМT).

ЦЕЛЬ: установить корреляцию между избыточной массой тела/ожирением и результатами лечения бесплодия методом ЭКО по частоте наступления клинической беременности (ЧНБ), ее исходам и массой плода при рождении.

МАТЕРИАЛЫ И МЕТОДЫ: исследование ретроспективное. Проанализированы данные историй болезни 1583 пациенток в возрасте от 21 до 45 лет (медиана 33,0 года [30,0;37,0]), прошедших лечение бесплодия методом ЭКО в период с 01.2012 по 12.2019 гг. Критерии исключения: дефицит массы тела (ИМТ $<18,5$ кг/м²), синдром поликистозных яичников, программы с использованием донорских ооцитов, эктопические беременности, оплодотворение эпидидимальными/тестикулярными сперматозоидами партнера. Статистическая обработка данных проводилась с использованием пакета прикладных программ STATISTICA (StatSoft). Пороговый уровень статистической значимости $<0,05$.

РЕЗУЛЬТАТЫ: до начала индукции суперовуляции в протоколе ЭКО пациенткам проводилось антропометрическое исследование: измерение роста и веса с расчетом индекса массы тела (ИМТ) (медиана $\left.23 \mathrm{k} \Gamma / \mathrm{M}^{2}[20,7 ; 26,2]\right)$.

Пациентки были разделены на 5 групп в зависимости от показателя ИМТ: группа 1 с нормальной массой тела (НМТ) - n=1061, гр. 2 (ИзбМТ) - n=368, гр. 3 (ожирение I ст.) - n=117, гр. 4 (ожирение II ст.) $\mathrm{n}=36$ чел., гр. 5 (ожирение III ст.) - n=1. В каждой группе оценивалась частота наступления клинической беременности (ЧНКБ) и ее исход: частота самопроизвольных абортов (СА), преждевременных (ПР), своевременных родов (СР) маловесными детьми (масса при рождении<2500г), новорожденных с НМТ (2500-3999 г.) и родов крупным плодом (ЧР/КП) ( $\geq 4000$ г) среди пациенток с одноплодной беременностью.

ЧНКБ по группам статистически не различалась: 34,6\%, 34,5\%, 30,7\%, 41,7\%, у пациентки гр. 5 наступила маточная одноплодная беременность, исход которой остался неизвестным.

В результате лечения наступило 542 беременности: 407 одноплодных (74,4\%), 132 двойни (24,1\%) и 3 тройни (0,5\%).

Беременность завершилась СР при одноплодной беременности: 71.9\%, 67,6\%, 70,8\%, 60,0\%; ПР 7,7\%, 5,4\%, 8,3\%, 0,0\%; СА в 1 триместре беременности - 18,3\%, 25,7\%, 20,8\%, 40,0\%; СА во 2 триместре 2,13\%, по 1,4\% в группах 2, 3 и 4 соответственно.

Частота родов маловесными детьми составила 8,8, 11,4, 6,3, 0\%; новорожденные с НMT - 84,9\%, 84,1\%, 75,0\%, 60,0\%; ЧР/КП - 6,3, 4,6, 18,8, 40,0 соответственно.

ВЫВОДЫ: при проведении корреляционного анализа зависимости ЧНКБ и ее исходов от ИМТ пациентки не выявлено ( $p=0,975$ и $p=0,469$ соответственно). ЧР/КП достоверно чаще встречалась у пациенток с ожирением ( $p=0,0016)$. Необходимо определить большую проспективную группу для расширения спектра оцениваемых параметров влияния массы тела на исходы лечения бесплодия методом ЭКО. 